\title{
MICROBIAL GENETICAL STUDIES OF Pseudomonas aeruginosa BACTERIA ISOLATED FROM HUMAN. Hassan, Amina A. ${ }^{1}$; M. K. Amin ${ }^{1}$; M.A.H. Youssef ${ }^{1}$ and M. El-Hussieny ${ }^{2}$ 1.Genetics Department, Fac. of Agric. Zag. Univ. Zagazig, Egypt 2.Microbiology Department, Fac. Pharmacy, Zag Univ. Zagazig, Egypt
}

\begin{abstract}
Pseudomonas aeruginosa bacterial isolates which isolated from human, were used to study some microbial genetical properties. Nutritional requirements were tested, the results showed that all the 17 isolates were prototrophs. Lysogenicity test demonstrated that all 17 isolates were lysogenic with one prophage,since every phage released from a lysogenic isolate was not able to lysis the same host cells. Host range of phage released from a lysogenic isolates was varied, and reached up to $65 \%(\phi 43)$. The phage released spontaneously from lysogens has been titered, phage $(\phi 50)$ resulted in high titration $\left(3.56 \times 10^{7} \mathrm{Pfu} / \mathrm{ml}\right)$. The ability of phage released from lysogen to lysis of the standard strains (PA01, PU21, MAM2) was tested. Phage $(\phi 50)$ had the ability to make lysis on the three strains.

Sensitivity of the bacterial isolates to some antibiotics (streptomycin, tetracycline, ampicillin, penicillin and chloramphenichol) was tested. Sensitivity was varied, depended on type, concentration of antibiotic and type of isolate. The effect of temperature on efficiency of plating for five phage lysates had been investigated. No plaques have been detected at low temperatures $\left(5\right.$ and $\left.15^{\circ} \mathrm{C}\right)$ or at high temperature $\left(45^{\circ} \mathrm{C}\right)$. Transducing ability of five phage lysates spontaneously released from lysogens was assessed. The $\phi 37$ and $\phi 78$ were able to transduce successfully the streptomycin, tetracycline, ampicillin and chloramphenicol resistance genes $\left(5.0 \times 10^{-6}, 1.73 \times 10^{-7}, 1.43 \times 10^{-4}, 8.8 \times 10^{-3}\right.$ and $7.2 \times 10^{-5}, 4.6 \times 10^{-5} \quad, 1.25 \times 10^{-5}, 6.2 \times 10^{-3}$ respectively).

The phage induced by ultraviolet irradiation was used in transduction assay. The Pfu/ml was increased. Transduction by lysogenic bacterial isolates was assessed. The results showed that transduction frequency was lower than in transduction by lysate.
\end{abstract}

Keywords: Bacteria, bacteriophage, transduction, titration, antibiotics.

\section{INTRODUCTION}

Pseudomonas species are plant, animal, and human pathogens, exhibit plant pathogen-suppressing properties useful is biological control, or express metabolic versatilities valued in biotechnology and bioremediation (Widmer et al., 1998). Specific detection of pseudomonas species in the environment could help us gain a more complete understanding of the ecological significance of these microorganisms.

The genus pseudomonas, was described as a genus of gramnegative, rod shaped microorganisms (Palleroni, 1984) and had been subject to repeated taxonomic revisions (Palleroni, 1993).

The genus pseudomonas includes species with functions of ecological, economic, and health-related importance. Some species are pathogenic for plants (Stead, 1992), while others are pathogenic for animals or human (Gilligan, 1991; Palleroni, 1992; Hobden, 2002). Some species exhibit plant 
growth promoting and pathogen suppressing functions and may be exploited for use in biological control (Keel et al., 1996), bioremediation (Palleroni, 1993) and biodegradation a variety of compounds (Guerin and Boyd, 1995; Grimberg et al., 1996). Investigation of new Pseudomonas aeruginosa isolates would represent a valuable tool in ecological, genetical and diagnostic studies of this genus.

The objective of this study was to study some microbial genetical properties of some Pseudomonas aeruginosa bacteria isolated as human pathogens. The isolation was carried out in the Hospital of Zagazig University and fully microbiologically characterized in the Dept. of Microbiology Fac of Pharmacy, Zagazig University. This study was carried out in Microbial Lab., Genetics Dept., Agric.Fac.,Zagazig Univ.

\section{MATERIALS AND METHODS}

\section{1- Bacteria and bacteriophages:}

Pseudomonas aeruginosa strains (PA01, PU21 and MAM2) were obtained from M. Day, University of Wales, College of Cardiff, UK and the bacterial isolates of Pseudomonas aeruginosa that have been used in this study were obtained from M.EL-Hussieny, Faculty of Pharmacy, Zagazig University, (Table 1). The generalized F116 and AMSE 2000 bacteriophages have been used in this study.

Table 1: The bacterial strains and isolates of Pseudomonas aeruginosa that were used in this study.

\begin{tabular}{|c|c|c|}
\hline $\begin{array}{l}\text { Strains and } \\
\text { isolates }\end{array}$ & Genotype & Reference \\
\hline PA 01 & Prototrophic, Str ${ }^{\mathrm{s}}$, Tet ${ }^{\mathrm{s}}$. & Holloway and Morgan (1986) \\
\hline PU 21 & $\mathrm{Str}^{\mathrm{s}}, \mathrm{Tet}^{\mathrm{s}}, \mathrm{Val}^{-}$ & Amin and Day (1988) \\
\hline MAM2 & $\mathrm{Str}^{\mathrm{s}}, \mathrm{Tet}^{\mathrm{s}}, \mathrm{Met}^{-}$ & Amin et al., (1987) \\
\hline ATC 1 & ( & Fac.pharmacy,Zagazig Univ. \\
\hline ATC 11 & - & Fac.pharmacy,Zagazig Univ. \\
\hline ATC 17 & - & Fac.pharmacy,Zagazig Univ. \\
\hline ATC 37 & - & Fac.pharmacy,Zagazig Univ. \\
\hline ATC 43 & - & Fac.pharmacy,Zagazig Univ. \\
\hline ATC 45 & - & Fac.pharmacy,Zagazig Univ. \\
\hline ATC 50 & - & Fac.pharmacy,Zagazig Univ. \\
\hline ATC 58 & - & Fac.pharmacy,Zagazig Univ. \\
\hline ATC 68 & - & Fac.pharmacy,Zagazig Univ. \\
\hline ATC 70 & - & Fac.pharmacy,Zagazig Univ. \\
\hline ATC 76 & - & Fac.pharmacy,Zagazig Univ. \\
\hline ATC 77 & - & Fac.pharmacy,Zagazig Univ. \\
\hline ATC 78 & - & Fac.pharmacy,Zagazig Univ. \\
\hline ATC 87 & - & Fac.pharmacy,Zagazig Univ. \\
\hline ATC 111 & - & Fac.pharmacy,Zagazig Univ. \\
\hline ATC 113 & - & Fac.pharmacy,Zagazig Univ. \\
\hline ATC 114 & - & Fac.pharmacy,Zagazig Univ. \\
\hline \multicolumn{2}{|c|}{$\begin{array}{l}\text { Strs }^{\text {s }}=\text { Streptomycin sensitive. } \\
\text { Tet }^{\text {s }}=\text { Tetracycline sensitive. }\end{array}$} & $\begin{array}{l}\text { Val }{ }^{-}=\text {Valine auxotroph. } \\
\text { Met }^{-}=\text {Methionine auxotroph }\end{array}$ \\
\hline
\end{tabular}

\section{2- Growth media:}

The nutrient agar (NA), nutrient broth (NB) and minimal media (MM) were used. Soft agar $(0.8 \% \mathrm{w} / \mathrm{v}$ agar) was prepared in distilled water and 
kept at $45^{\circ} \mathrm{C}$ on waterbath. Phosphate buffer was prepared from 1/ $15 \mathrm{M}$ potassium phosphate $\left(\mathrm{KH}_{2} \mathrm{PO}_{4}\right)$ and $1 / 15 \mathrm{M}$ disodium phosphate $\left(\mathrm{Na}_{2} \mathrm{HPO}_{4} .2 \mathrm{H}_{2} \mathrm{O}\right)$. The antibiotics (streptomycin, tetracycline, ampicillin, pencillin and chloramphenichol) were added as sterilized solutions by filtration through $0.2 \mu \mathrm{m}$ filter membrane to the media after autoclaving.

\section{3- Nutritional requirements:}

This experiment was performed by streaking the bacterial isolates on complete and minimal media.

\section{4- Lysogenesity test:}

Each isolate cells were inoculated into $10 \mathrm{ml}$ of NB medium, then placed on a shaker incubator overnight at $30^{\circ} \mathrm{C}$. A few drops of chloroform were added and centrifugation was carried out at $10000 \mathrm{rpm}$ for $15 \mathrm{~min}$. the supernatant was removed and passed through a sterile membrane $(0.2 \mu \mathrm{m})$. the supernatant was assayed by using the spot test method (Barrangou et al., 2002). The plate inoculum consisted of $3 \mathrm{ml}$ of soft agar mixed with $100 \mu \mathrm{l}$ of an overnight host culture. This mixture was briefly vortexed and spread onto the surface of an agar plate. Single drops of each supernatant were spotted onto inculated agar plates, and the plates were incupated overnight at $30^{\circ} \mathrm{C}$. Bacterial sensitivity of a bacteriophage was establish by bacterial lysis at the spot where the supernatant drop was deposited.

\section{5- Phage titration:}

The double-agar-layer method(Park et al., 2000 and Sharma et al.,2002)was used. Serial hundred-fold dilutions of phage lysate were prepared in phosphate butter $(\mathrm{PH} 7.0)$. Equal volumes $(0.1 \mathrm{ml})$ of phage lysate and host cells (grown overnight in NB at $30^{\circ} \mathrm{C}$ ) were mixed in $3 \mathrm{ml}$ of soft molten agar. The mixture was vortexed and poured immediately onto NA plate. Plates were incubated at $30^{\circ} \mathrm{C}$ for overnight. Plaques were counted and the number of plaque forming units (pfu/ $\mathrm{ml}$ ) was calculated.

\section{6- Isolation and purification bacteriophage from lysogen:}

After titration, five phages ( $\phi 37, \phi 43, \phi 50, \phi 78$ and $\phi 111)$ were isolated and purified by single-plaque isolation. Well-isolated plaques were cut from agar plates, placed in sterile diluent and used to produce new phage lysates. This procedure was repeated through three cycles or until produced only a single-plaque morphology(Jensen et al., 1998 and Chakrabarti et al., 2000).

\section{7- Phage host range:}

Many strains and isolates of Pseudomonas aeruginosa have been used to study host range of phages released spontaneously from lysogenic isolates. The phage lysates were spotted onto layer of bacterial host .

\section{8- The efficiency of plating(EOP):}

This experiment was performed by titration of five phage isolates $(\phi 37$, $\phi 43, \phi 50, \phi 78$ and $\phi 111)$ on NA plates and incubated at different temperatures $(5,15,19,25,30,35,40$ and 45$)$. The number of plaques were recorded and the $\mathrm{pfu} / \mathrm{ml}$ was calculated.

\section{9- Sensitivity to antibiotics:}

The five antibiotics that have been used in this experiment were streptomycin, Ampicillin, tetracycline, penicillin and chloramphenichol. Different concentrations of each antibiotic $(100,250,400,500,1000,1200$ 
and $1500 \mu \mathrm{g} / \mathrm{ml}$ ) have been added to NA plates. All 17 isolates were streaked onto the plates which contain antibiotic and plates without antibiotic and incubated at $30^{\circ} \mathrm{C}$ for $2-3$ days.

10- Transduction by lysate of released phages spontaneously from lysogenic isolates:

The lysogenic isolates (ATC37, ATC 43, ATC 50, ATC 78 and ATC 111) were inoculated into $10 \mathrm{ml}$ of $\mathrm{NB}$ and incubated at $30^{\circ} \mathrm{C}$ for overnight. The cultures were centrifuged at $10000 \mathrm{rpm}$ for $15 \mathrm{~min}$ and filtered through $0.2 \mu \mathrm{m}$ filter membrane. The phage lysates were titered and equal volumes $(1.0 \mathrm{ml})$ of phage lysate and recipient cells were mixed. The mixture was kept for 20 to $30 \mathrm{~min}$ at room temperature to allow phage adsorption ( Toth et al., 2003). Serial dilutions have been prepared and placed onto selective media, The plates were incubated at $30^{\circ} \mathrm{C}$. Number of transductants were recorded and transduction frequency was calculated. In other experiment, the plates were incubated at different temperature $\left(5,15,19,25,30,35,40\right.$ and $\left.45^{\circ} \mathrm{C}\right)$.

11- Transduction by induced phage by ultraviolet irradiation:

$10 \mathrm{ml}$ of overnight cultures were placed on petri dish. The plates were exposed to ultraviolet lamb for $25 \mathrm{~min}$, centrifuged, filtered and titered. The induced phages were used to transduce different markers.

\section{2- Transduction by lysogenic isolates:}

The donor and recipient cells were grown independently in NB overnight at $30^{\circ} \mathrm{C}$. One $\mathrm{ml}$ of donor and recipient was layered onto separate nitrocellulose filter membrane $(0.2 \mu \mathrm{m})$. The two membranes were placed face-to-face on NA plate and incubated at $30^{\circ} \mathrm{C}$ for $24 \mathrm{~h}$. After incubation time, the membrane filters were vortexed for $60 \mathrm{sec}$ in $10 \mathrm{ml}$ phosphate buffer $(\mathrm{pH}$ 7.0). Serial dilutions have been prepared and placed onto selective media to count the donor, recipient and transductants. The phage particles was also calculated.

\section{1- Nutritional requirements:}

\section{RESULTS AND DISCUSSION}

Data in Table 2 show that all the pathogenic bacterial isolates of $P$. aeruginosa that have been isolated from human are prototrophs. Since all the 17 isolates were able to grow on complete or minimal media.

\section{2- Lysogenicity ability:}

Data is Table 3 represent the lysogenicity ability of the 17 isolates of $P$. aeruginosa, it seems that all the isolates were lysosenic with one prophage. That is because every phage released spontaneously from the same lysogenic was not able to lysis the same host cells because of lysogenic immunity.

\section{3- Host range of phage released form lysogens:}

The host range of phage released from the lysogens was varied (Table $4)$. Phage lysate ( $\phi 43)$ was able to induce lysis in 11 isolates of 17 with high percentage of host range reached up to $65 \%$ of tested isolates. In addition, the same host isolate (ATC 43) had been infected by 13 phage lysates of 17 lysates $(77 \%$ of the tested phage lysate). However, phages, $\phi 76$ and $\phi 83$ have a narrow host range, since they were able to induce lysis in three host 
only (With a percentage of $18 \%$ of isolates tested). The phage released form lysogens were selectively lytic against some bacterial isolates but were not observed to lyse others, this observation is common in phage isolated from environments. A temperate phage isolated from sewage does form plaque on strain $\mathrm{H}$ of $E$. coli, but was not able to form plaque on neither strain $\mathrm{C}$ and K12 of E. coil, nor on strain L12 of Salmonella spp (Dhillon et al., 1998).

Table 2: Nutritional requirements of $P$. aeruginosa bacteria isolated from human.

\begin{tabular}{|l|c|c|}
\hline \multicolumn{1}{|c|}{ Media } & CM & MM \\
\hline Strain & + & + \\
\hline ATC 1 & + & + \\
\hline ATC 11 & + & + \\
\hline ATC 17 & + & + \\
\hline ATC 37 & + & + \\
\hline ATC 43 & + & + \\
\hline ATC 45 & + & + \\
\hline ATC 50 & + & + \\
\hline ATC 58 & + & + \\
\hline ATC 68 & + & + \\
\hline ATC 70 & + & + \\
\hline ATC 76 & + & + \\
\hline ATC 77 & + & + \\
\hline ATC 78 & + & + \\
\hline ATC 87 & + & + \\
\hline ATC 111 & + & \\
\hline ATC 113 & + & + \\
\hline ATC 114 & + & + \\
\hline
\end{tabular}

$+=$ Growth.

\section{4- Titration of released phage:}

The ability of phage released spontaneously from lysogens has been assessed using one proper host bacterial cells (Table 5). Phage ( $\phi 50)$ results in high titration $\left(3.56 \times 10^{7} \mathrm{pfu} / \mathrm{ml}\right)$ upon using with isolate ATC 68. These results clearly show that the occurrence of naturally lysogenic bacteria among Pseudomonas aeruginosa isolates from human among the tested ones reached up to $100 \%$.

\section{5-Lysis of standard strains of Pseudomonas aeruginosa by phage released from isolated lysogens.}

All the phage lysates that released from the pathogenic isolates have been allowed to induce lysis with three standard strains of $P$. aeruginosa (Table 6) phage $(\phi 50)$ had the ability to make lysis in the three standard strains, PA01, PU21, and MAM2.

\section{6- Lysis of isolated $P$. aeruginosa bacterial cells by standard phage} particles:

Data in Table 7 illustrate the ability of two standard bacteriophages of $P$. aeruginosa, F116 and AMSE2000 to form lysis in the human $P$. aeruginosa isolates. Bacteriophages F116 and AMSE2000 were not able to lysis the lysogenic isolates ATC: $1,45,70,78,87$, and 114 . This means that the phages that are lysogenized these isolates may be belong to the same group of the standard phages, F116 and AMSE2000 because of the lysogenic immunity property. 
Hassan, Amina A.et al.

3-4

3444 
J. Agric. Sci. Mansoura Univ., 32 (5), May, 2007

Table 5: Titration of phage released with proper host cells.

\begin{tabular}{|c|c|c|}
\hline phage & Host & Pfu/ ml \\
\hline$\phi 1$ & ATC 68 & $2.32 \times 10^{5}$ \\
\hline$\phi 11$ & ATC 43 & $4.0 \times 10^{3}$ \\
\hline$\phi 17$ & ATC 43 & $8.0 \times 10^{3}$ \\
\hline$\phi 37$ & ATC 87 & $9.2 \times 10^{4}$ \\
\hline$\phi 43$ & ATC 58 & $7.0 \times 10^{3}$ \\
\hline$\phi 45$ & ATC 58 & $3.4 \times 10^{5}$ \\
\hline$\phi 50$ & ATC 68 & $3.56 \times 10^{7}$ \\
\hline$\phi 58$ & ATC 45 & $2.7 \times 10^{4}$ \\
\hline$\phi 68$ & ATC 70 & $5.5 \times 10^{4}$ \\
\hline$\phi 70$ & ATC 78 & $8.0 \times 10^{3}$ \\
\hline$\phi 76$ & ATC 11 & $1.42 \times 10^{3}$ \\
\hline$\phi 77$ & ATC 37 & $6.0 \times 10^{3}$ \\
\hline$\phi 78$ & ATC 77 & $1.76 \times 10^{5}$ \\
\hline$\phi 87$ & ATC 76 & $8.5 \times 10^{4}$ \\
\hline$\phi 111$ & ATC 43 & $1.3 \times 10^{4}$ \\
\hline$\phi 113$ & ATC 1 & $9.6 \times 10^{4}$ \\
\hline$\phi 114$ & ATC 113 & $1.73 \times 10^{5}$ \\
\hline
\end{tabular}

However, phages F116 and AMSE2000 were able to lysis isolates, ATC: $11,17,37,43,50,58,68,76,77,111$ and 113 (with about $65 \%$ of isolates). So, these released phage particles may be do not belong to the same group of phages F116, and AMSE2000. These results need further molecular analysis to find the genetic relationship between the isolated phages and the two standard.

Table 6: Lysis of standard strains.

\begin{tabular}{|c|c|c|c|}
\hline Phage Host & PA 01 & PU 21 & MAM2 \\
\hline$\phi 1$ & - & + & - \\
\hline$\phi 11$ & - & - & - \\
\hline$\phi 17$ & - & - & - \\
\hline$\phi 37$ & - & - & + \\
\hline$\phi 43$ & - & + & - \\
\hline$\phi 45$ & - & - & - \\
\hline$\phi 50$ & + & - & - \\
\hline$\phi 58$ & - & - & - \\
\hline$\phi 68$ & - & - & - \\
\hline$\phi 70$ & - & - & - \\
\hline$\phi 76$ & - & - & - \\
\hline$\phi 77$ & - & - & - \\
\hline$\phi 78$ & + & - & - \\
\hline$\phi 87$ & - & - & - \\
\hline$\phi 111$ & - & - & - \\
\hline$\phi 113$ & + & & - \\
\hline$\phi 114$ & - & & - \\
\hline
\end{tabular}

\section{7- Sensitivity to antibiotics:}

Data in Table 8 show the sensitivity of the bacterial isolates to five different antibiotics. The same concentrations have been used with each antibiotic. 
Hassan, Amina A.et al.

Table 7: Lysis of standard phages.

\begin{tabular}{|l|c|c|}
\hline Host & F 116 & AMSE 2000 \\
\hline ATC 1 & - & - \\
\hline ATC 11 & + & + \\
\hline ATC 17 & + & + \\
\hline ATC 37 & + & + \\
\hline ATC 43 & + & + \\
\hline ATC 45 & - & - \\
\hline ATC 50 & + & + \\
\hline ATC 58 & + & + \\
\hline ATC 68 & + & - \\
\hline ATC 70 & - & + \\
\hline ATC 76 & + & + \\
\hline ATC 77 & + & - \\
\hline ATC 78 & - & - \\
\hline ATC 87 & - & + \\
\hline ATC 111 & + & + \\
\hline ATC 113 & + & - \\
\hline ATC 114 & - & \\
\hline
\end{tabular}

Table 8: Sensitivity to antibiotics.

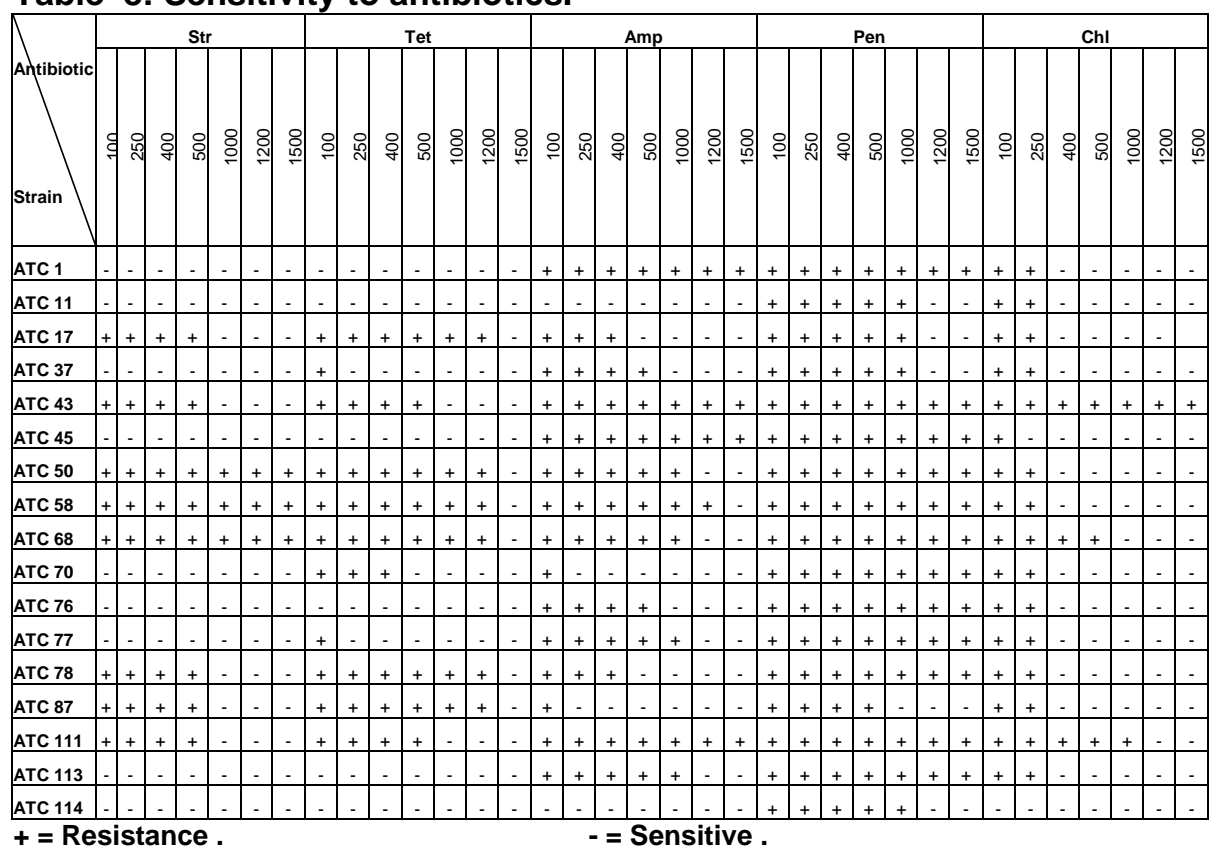

\section{8- Effect of temperature on the efficiency of plating:}

The influence of temperature on the efficiency of five phage lysates plating with bacterial host has been investigated (Table 9). No plaques have been detected at low temperatures, 5 and $15^{\circ} \mathrm{C}$ or at high temperature, $45^{\circ} \mathrm{C}$. The optimum temperature of plating phages $\phi 43,50,78$, and 111 was $35^{\circ} \mathrm{C}$ (pfu/ml ranged from 0.01 up to $\left.3.11 \times 10^{10}\right)$. 
Table 9: Effect of temperature on efficiency of plating.

\begin{tabular}{|c|c|c|c|c|c|c|c|c|}
\hline \multirow{2}{*}{ Phage } & \multicolumn{7}{|c|}{ Pfu/ ml + Temperature $\left({ }^{\circ} \mathbf{C}\right)$} \\
\cline { 2 - 9 } & $\mathbf{5}$ & $\mathbf{1 5}$ & $\mathbf{1 9}$ & $\mathbf{2 5}$ & $\mathbf{3 0}$ & $\mathbf{3 5}$ & $\mathbf{4 0}$ & $\mathbf{4 5}$ \\
\hline$\phi 37$ & - & - & $3.0 \times 10^{7}$ & $7.0 \times 10^{7}$ & $2.9 \times 10^{8}$ & $1.6 \times 10^{8}$ & $1.4 \times 10^{8}$ & - \\
\hline$\phi 43$ & - & - & $3.72 \times 10^{9}$ & $6.0 \times 10^{7}$ & $1.78 \times 10^{10}$ & $3.11 \times 10^{10}$ & $2.53 \times 10^{10}$ & - \\
\hline$\phi 50$ & - & - & $2.0 \times 10^{7}$ & $3.0 \times 10^{5}$ & $7.0 \times 10^{7}$ & $0.01 \times 10^{10}$ & $1.2 \times 10^{8}$ & - \\
\hline$\phi 78$ & - & - & $7.1 \times 10^{7}$ & $8.2 \times 10^{8}$ & $1.56 \times 10^{10}$ & $2.36 \times 10^{10}$ & $1.82 \times 10^{10}$ & - \\
\hline$\phi 111$ & - & - & $3.1 \times 10^{8}$ & $4.0 \times 10^{7}$ & $4.2 \times 10^{9}$ & $0.73 \times 10^{10}$ & $5.68 \times 10^{9}$ & - \\
\hline
\end{tabular}

9- Effect of temperature on transduction:

No transductants have been formed on temperatures, 5,15 and $45^{\circ} \mathrm{C}$. The optimum temperature for transduction ranged from $30-35^{\circ} \mathrm{C}$. This may depend on the phage lysate and transduced marker (Table 10).

Table 10: Effect of temperature on transduction mechanism.

\begin{tabular}{|c|c|c|c|c|c|c|c|c|c|c|}
\hline $\begin{array}{l}\frac{\mathscr{D}}{8} \\
\frac{\pi}{\alpha}\end{array}$ & 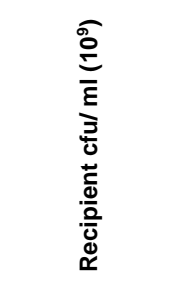 & 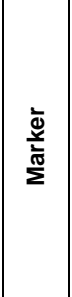 & 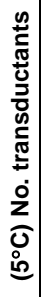 & 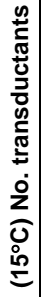 & 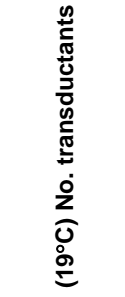 & 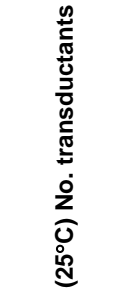 & 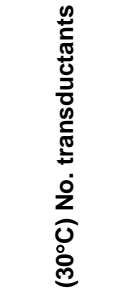 & 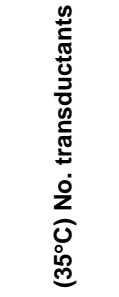 & 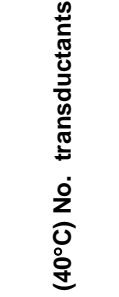 & 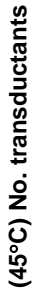 \\
\hline \multirow[t]{4}{*}{$\phi 37$} & ATC $77=1.46$ & Str & - & - & $2.0 \times 10^{1}$ & $8.0 \times 10^{1}$ & $2.7 \times 10^{2}$ & $1.2 \times 10^{2}$ & $1.1 \times 10^{2}$ & - \\
\hline & & Tet & - & - & - & - & - & - & - & - \\
\hline & & Amp & - & - & $2.4 \times 10^{1}$ & $2.4 \times 10^{4}$ & $2.23 \times 10^{5}$ & $8.5 \times 10^{4}$ & $6.7 \times 10^{4}$ & - \\
\hline & ATC $114=2.2$ & Chl & - & - & $1.3 \times 10^{5}$ & $1.3 \times 10^{5}$ & $9.1 \times 10^{6}$ & $6.8 \times 10^{7}$ & $3.8 \times 10^{6}$ & - \\
\hline \multirow[t]{4}{*}{$\phi 43$} & ATC 114 & Str & - & - & - & - & $3.0 \times 10^{1}$ & - & - & - \\
\hline & $=2.2$ & Tet & - & - & - & - & - & - & - & - \\
\hline & & Amp & - & - & $1.37 \times 10^{3}$ & $1.42 \times 10^{3}$ & $1.43 \times 10^{3}$ & $6.2 \times 10^{2}$ & $4.3 \times 10^{2}$ & - \\
\hline & & $\mathrm{Chl}$ & - & - & $2.47 \times 10^{2}$ & $4.5 \times 10^{4}$ & $1.78 \times 10^{7}$ & $8.3 \times 10^{6}$ & $6.1 \times 10^{6}$ & - \\
\hline \multirow[t]{3}{*}{$\phi 50$} & ATC 77 & Str & - & - & $1.1 \times 10^{2}$ & $1.2 \times 10^{2}$ & $1.5 \times 10^{2}$ & $7.0 \times 10^{1}$ & $5.0 \times 10^{1}$ & - \\
\hline & $=1.46$ & Tet & - & - & - & & - & & & - \\
\hline & & Amp & - & - & $1.7 \times 10^{3}$ & $4.8 \times 10^{3}$ & $7.3 \times 10^{4}$ & $6.1 \times 10^{4}$ & $5.3 \times 10^{4}$ & - \\
\hline \multirow[t]{4}{*}{$\phi 78$} & ATC 114 & Str & - & - & $1.0 \times 10^{1}$ & $1 \times 10^{1}$ & $5 \times 10^{1}$ & $2 \times 10^{1}$ & $1.0 \times 10^{1}$ & - \\
\hline & $=2.2$ & Tet & - & - & & - & - & - & & - \\
\hline & & Amp & - & - & $2.72 \times 10^{3}$ & $1.19 \times 10^{4}$ & $2.5 \times 10^{4}$ & $1.7 \times 10^{3}$ & $1.49 \times 10^{3}$ & - \\
\hline & & $\mathrm{Chl}$ & - & - & $3.5 \times 10^{3}$ & $2.1 \times 10^{5}$ & $6.8 \times 10^{7}$ & $8.9 \times 10^{6}$ & $7.2 \times 10^{6}$ & - \\
\hline \multirow[t]{4}{*}{$\phi 111$} & ATC 114 & Str & - & - & $5.7 \times 10^{2}$ & $2.97 \times 10^{3}$ & $1.9 \times 10^{4}$ & $7.2 \times 10^{3}$ & $5.0 \times 10^{3}$ & - \\
\hline & $=1.46$ & Tet & - & - & - & - & - & - & - & - \\
\hline & & Amp & - & - & $2.12 \times 10^{3}$ & $3.1 \times 10^{3}$ & $1.8 \times 10^{4}$ & $1.37 \times 10^{3}$ & $5.1 \times 10^{2}$ & - \\
\hline & & Chl & - & - & $2.16 \times 10^{2}$ & $3.1 \times 10^{4}$ & $7.9 \times 10^{6}$ & $8.0 \times 10^{6}$ & $6.9 \times 10^{6}$ & - \\
\hline
\end{tabular}

10- Transduction by lysate of phages released from lysogenic isolates:

The phages released spontaneously from lysogenic isolates ATC37, ATC43, ATC50, ATC78 and ATC111 were used. The $\phi 37$ was able to transduce successfully the streptomycin, tetracycline, ampcillin and chloramphenicol resistance genes to strains ATC76, ATC77, ATC87 and 
ATC114 respectively. The transduction frequency was $5.0 \times 10^{-6}, 1.73 \times 10^{-7}$, $1.43 \times 10^{-4}$ and $8.8 \times 10^{-3}$. The $\phi 78$ also was able to transduce the same markers $\left(7.2 \times 10^{-5}, 4.6 \times 10^{-5}, 1.25 \times 10^{-5}\right.$ and $\left.6.2 \times 10^{-3}\right)$. The two phage isolate $\phi 50$ and $\phi 111$ were not able to transduce tetracycline resistance gene. Data in Table 11 shows that the five phage isolates were able to transduce more than one marker at range from $1.73 \times 10^{-7}$ to $2.3 \times 10^{-3}$, so it may be generalized transducing phages.

Table 11: Transduction by spontaneously released phages from lysogenic isolates.

\begin{tabular}{|c|c|c|c|c|}
\hline $\begin{array}{c}\text { Phage } \\
\text { Pfu/ml (107) }\end{array}$ & $\begin{array}{c}\text { Recipient } \\
\text { Cfu/ ml }\left(10^{9}\right)\end{array}$ & Marker & No. transductants & $\begin{array}{c}\text { Transduction } \\
\text { frequency }\end{array}$ \\
\hline \multirow[t]{2}{*}{$\phi 37$} & ATC $76=2.72$ & Str & $1.38 \times 10^{4}$ & $5.0 \times 10^{-6}$ \\
\hline & ATC $77=9.48$ & Tet & $1.64 \times 10^{3}$ & $1.73 \times 10^{-7}$ \\
\hline \multirow[t]{2}{*}{7.28} & ATC $87=1.34$ & Amp & $1.92 \times 10^{5}$ & $1.43 \times 10^{-4}$ \\
\hline & ATC $114=6.9$ & $\mathrm{Chl}$ & $6.1 \times 10^{7}$ & $8.8 \times 10^{-3}$ \\
\hline$\phi 43$ & ATC $78=1.6$ & Amp & $5.3 \times 10^{3}$ & $3.31 \times 10^{-6}$ \\
\hline 2.79 & ATC $58=1.78$ & $\mathrm{Chl}$ & $3.9 \times 10^{2}$ & $2.2 \times 10^{-7}$ \\
\hline$\phi 50$ & ATC $43=1.48$ & Str & $7.88 \times 10^{5}$ & $5.32 \times 10^{-4}$ \\
\hline \multirow[t]{2}{*}{3.56} & ATC $77=9.26$ & Tet & - & \\
\hline & & Chl & $5.2 \times 10^{3}$ & $5.6 \times 10^{-7}$ \\
\hline \multirow[t]{2}{*}{$\phi 78$} & ATC $43=1.48$ & Tet & $1.08 \times 10^{5}$ & $7.2 \times 10^{-5}$ \\
\hline & ATC $77=9.48$ & Str & $4.38 \times 10^{5}$ & $4.6 \times 10^{-5}$ \\
\hline \multirow[t]{2}{*}{2.96} & ATC $70=3.16$ & Amp & $3.96 \times 10^{4}$ & $1.25 \times 10^{-5}$ \\
\hline & ATC $114=6.9$ & $\mathrm{Chl}$ & $4.3 \times 10^{7}$ & $6.2 \times 10^{-3}$ \\
\hline \multirow[t]{2}{*}{$\phi 111$} & ATC $114=6.9$ & Str & $3 \times 10^{3}$ & $4.35 \times 10^{-7}$ \\
\hline & & Tet & - & - \\
\hline \multirow[t]{3}{*}{3.62} & & Amp & $1.56 \times 10^{7}$ & $2.3 \times 10^{-3}$ \\
\hline & ATC $58=1.78$ & Chl & $1.71 \times 10^{4}$ & $9.6 \times 10^{-6}$ \\
\hline & ATC $78=1.6$ & Amp & $4.6 \times 10^{3}$ & $2.88 \times 10^{-6}$ \\
\hline
\end{tabular}

\section{1-Transduction by ultraviolet irradiation induced phages:}

The results of this study showed that the number of induced phage upon exposure to ultraviolet irradiation was increased $\left(8.12 \times 10^{7}, 3.11 \times 10^{7}\right.$, $3.78 \times 10^{7}, 3.7 \times 10^{9}$ and $3.96 \times 10^{7}$ for phages $\phi 37, \phi 43, \phi 50, \phi 78$ and $\phi 111$ respectively) (Table 12) comparing with phages spontaneously released $\left(7.28 \times 10^{7}, 2.79 \times 10^{7}, 3.56 \times 10^{7}, 2.96 \times 10^{7}\right.$ and $\left.3.62 \times 10^{7}\right)$. Taeok et al., (2006) found that phages that released spontaneously from Staphylococcus aureus, were artificially increased by adding mitomycin C. Prophage induction can be provoked by factors stimulating the SOS response. One could imagine that conditions in bioreactors stimulate the SOS response. The SOS induced Rec A protein triggers self - cleavage of the repressor, causing prophage induction (Czyz et al. 2001).

\section{2- Transduction by lysogenic bacterial isolates:}

The same previous lysogenic isolates were used as donor to compare transduction frequency by lysogen and by lysate. Table 13 shows that no any isolate was able to transduce tetracycline resistance gene. Also, 
transduction frequencies were lower upon using phage lysate. These results come agree with the results of Ashelford et al., (1999).

Table 12: Transduction by induced phages by ultraviolet irradiation.

\begin{tabular}{|c|c|c|c|c|}
\hline $\begin{array}{c}\text { Phage } \\
\text { Pfu/ml }\left(10^{7}\right)\end{array}$ & Recipient Cfu/ $\mathrm{ml}\left(10^{9}\right)$ & Marker & $\begin{array}{c}\text { No. } \\
\text { transductants }\end{array}$ & $\begin{array}{c}\text { Transduction } \\
\text { frequency }\end{array}$ \\
\hline \multirow[t]{2}{*}{$\phi 37$} & ATC $76=2.72$ & Str & $2.7 \times 10^{3}$ & $9.9 \times 10^{-7}$ \\
\hline & ATC $77=9.48$ & Tet & - & - \\
\hline \multirow[t]{2}{*}{8.12} & ATC $87=1.34$ & Amp & $5.1 \times 10^{3}$ & $3.8 \times 10^{-6}$ \\
\hline & ATC $114=6.9$ & Chl & $4.3 \times 10^{4}$ & $6.2 \times 10^{-6}$ \\
\hline$\phi 43$ & ATC $78=1.6$ & Amp & $1.5 \times 10^{3}$ & $9.4 \times 10^{-7}$ \\
\hline 3.11 & ATC $58=1.78$ & Chl & $6.7 \times 10^{2}$ & $3.76 \times 10^{-7}$ \\
\hline$\phi 50$ & ATC $43=1.48$ & Str & $3.0 \times 10^{1}$ & $2.02 \times 10^{-8}$ \\
\hline \multirow[t]{3}{*}{3.78} & ATC $77=9.26$ & Str & - & - \\
\hline & & Tel & - & - \\
\hline & & Chl & $3.6 \times 10^{2}$ & $3.88 \times 10^{-8}$ \\
\hline \multirow[t]{2}{*}{$\phi 78$} & ATC $43=1.48$ & Tet & - & - \\
\hline & ATC $77=9.48$ & Str & $2.0 \times 10^{2}$ & $2.1 \times 10^{-8}$ \\
\hline \multirow[t]{2}{*}{37.0} & ATC $70=3.16$ & Amp & $1.6 \times 10^{2}$ & $5.06 \times 10^{-8}$ \\
\hline & ATC $114=6.9$ & Chl & $5.1 \times 10^{4}$ & $7.4 \times 10^{-6}$ \\
\hline \multirow[t]{3}{*}{$\phi 111$} & ATC $114=6.9$ & Str & - & - \\
\hline & & Tet & - & - \\
\hline & & Amp & $5.6 \times 10^{2}$ & $8.1 \times 10^{-8}$ \\
\hline \multirow[t]{2}{*}{3.96} & ATC $58=1.78$ & Chl & $1.8 \times 10^{4}$ & $1.01 \times 10^{-5}$ \\
\hline & ATC $78=1.6$ & Amp & $1.1 \times 10^{2}$ & $6.9 \times 10^{-8}$ \\
\hline
\end{tabular}

Table 13: Transduction by lysogenic isolates.

\begin{tabular}{|c|c|c|c|c|c|c|}
\hline $\begin{array}{c}\text { Donor at 24h. } \\
\left(10^{5}\right)\end{array}$ & $\begin{array}{c}\text { Recipient at } \\
24 \mathrm{~h} .\left(10^{5}\right)\end{array}$ & $\begin{array}{c}\text { Phage at } \\
24 \mathrm{~h} .\end{array}$ & $\begin{array}{c}\text { Recipient } \\
\text { at zero } \\
\text { time. }\left(10^{9}\right)\end{array}$ & Marker & $\begin{array}{c}\text { No. } \\
\text { transductants }\end{array}$ & $\begin{array}{c}\text { Transduction } \\
\text { frequency. }\end{array}$ \\
\hline ATC $37=2.37$ & ATC $76=3.11$ & $8.7 \times 10^{4}$ & 2.72 & Str & $1.0 \times 10^{1}$ & $3.7 \times 10^{-9}$ \\
\hline ATC 37 $=0.96$ & ATC $77=2.56$ & $1.13 \times 10^{5}$ & 9.48 & Tet & - & - \\
\hline ATC $37=1.19$ & ATC $87=1.99$ & $1.7 \times 10^{6}$ & 1.34 & Amp & $1.2 \times 10^{2}$ & $8.96 \times 10^{-8}$ \\
\hline ATC $37=2.21$ & ATC114 = 2.6 & $1.46 \times 10^{5}$ & 6.9 & chl & $1.7 \times 10^{3}$ & $2.5 \times 10^{-7}$ \\
\hline ATC $43=2.43$ & ATC $78=3.17$ & $5.2 \times 10^{6}$ & 1.6 & Amp & - & - \\
\hline ATC $43=0.24$ & ATC $58=6.99$ & $6.5 \times 10^{6}$ & 1.78 & $\mathrm{Chl}$ & - & - \\
\hline ATC50 = 9.86 & ATC $43=1.1$ & $2.2 \times 10^{6}$ & 1.48 & Str & $3.0 \times 10^{1}$ & $2.03 \times 10^{-8}$ \\
\hline \multirow[t]{3}{*}{ ATC $50=3.56$} & ATC $77=2.13$ & $4.6 \times 10^{6}$ & 9.26 & Str & - & - \\
\hline & & & & Tet & - & - \\
\hline & & & & $\mathrm{Chl}$ & $5.0 \times 10^{1}$ & $5.4 \times 10^{-9}$ \\
\hline ATC $78=3.46$ & ATC $43=9.7$ & $8.4 \times 10^{6}$ & 1.48 & Tet & - & - \\
\hline ATC $78=9.65$ & ATC $77=1.06$ & $2.5 \times 10^{4}$ & 9.48 & Str & - & - \\
\hline ATC 78 $=4.25$ & ATC $70=1.24$ & $6.6 \times 10^{4}$ & 3.16 & Amp & $1.5 \times 10^{2}$ & $4.7 \times 10^{-8}$ \\
\hline ATC $78=3.71$ & ATC $114=3.28$ & $8.9 \times 10^{4}$ & 6.9 & $\mathrm{Chl}$ & $2.6 \times 10^{2}$ & $3.8 \times 10^{-8}$ \\
\hline \multirow[t]{3}{*}{ ATC111= 3.98} & ATC $114=2.46$ & $1.22 \times 10^{5}$ & 6.9 & Str & $1.0 \times 10^{1}$ & $1.44 \times 10^{-9}$ \\
\hline & & & & Tet & - & - \\
\hline & & & & Amp & $2.2 \times 10^{3}$ & $3.2 \times 10^{-8}$ \\
\hline ATC $111=4.59$ & ATC $58=6.68$ & $1.48 \times 10^{7}$ & 1.78 & $\mathrm{Chl}$ & $2.6 \times 10^{3}$ & $1.46 \times 10^{-6}$ \\
\hline ATC $111=3.98$ & ATC $78=7.39$ & $1.33 \times 10^{7}$ & 1.6 & Amp & $3.2 \times 10^{3}$ & $2.0 \times 10^{-6}$ \\
\hline
\end{tabular}

REFERENCES 
Amin, M., and M. Day. 1988. Donor and recipient effects on transduction frequency in situ. REGEM 1, 2 Cofs. Cardiff, UK.

Amin, M., M. Day and J. Fry. 1987. Transduction in water. European Meeting on Bacterial Genetics. Brussels, Belgium.

Ashelford, K. E., C. F. John, J. B. Mark, R. J. Aaron and J. D. Martin. 1999. Characterization of six bacteriophages of Serratia liquefaciens CP6 isolated from the sugar beet phytosphere. Applied and Environmental Microbiol., 65: 1959-1965.

Barrangou, R.,S. S. Yoon, F. Breidt, Jr., H. P. Fleming, and T. R. Klaenhammer. 2002. Characterization of siz Leuconostoc fallax bacteriophages isolated from an industrial sauerkraut fermentation. Applied and Environmental Microbiol., 68 :5452-5458.

Chakrabarti, A. K., A. N. Ghosh, G. Balakrish, S. K. Niyogl, S. K., Bhattacharya and B. L. Sarkar. 2000. Development and evaluation of a phage typing scheme for Vibrio cholerae O139.Journal of Clinical Microbiol., 38:44-49.

Czyz, A., M. Los, B. Wrobel and G. Wegrzyn. 2002. Inhibition of spontaneous induction of lambdoid prophage in Escherichia coli cultures: simple procedures with possible biotechnological applications. BMC Biotechnol. 1: 1.

Dhillon, T., A. Poon, D. Chan and A. Clark. 1998. General transducing phages like salmonella phage $P_{22}$ isolated using a smooth strain of Escherichia coli as host. FEMS Microbiol. Lett. 161, 129.

Gilligan, P. 1991 . Microbiology of airway disease in patient to with cystic fibrosis. Clin. Microloiol. Rev. 4: 35-51.

Grimberg, S., J. Stringfellow and D. Atken. 1996. Quantifying the biodegradation of phenanthrene by Pseudomonas stutzeri. Appl. Environ. Microbiol., 62: 2387-2392.

Guerin, W. and S. Boyd. 1995. Maintenance and induction of naphthalene degradation activity in Pseudomonas Putida. Appl. Environ. Microbiol., 61: 4061-4068.

Hobden, J. A. 2002. Pseudomonas aeruginosa proteases and corneal virulence. DNA and cell Biology, 21, 5-6: 391-396.

Holloway, B. and A. Morgan. 1986. Genome organization in Pseudomonas. Annual Review of Microbiol. 40: 69-105.

Jensen, E. C., H. S. Schrader, B. Rieland, T. L. Thompson, K. W. Lee, K. W. Nickerson and T. A. Kokjohn. 1998. Prevalence ofbroad-host-range lytic bacteriophages of Sphaerotilus natans, Escherichia coli, and Pseudomonas aeruginosa. Applied and Environmental Microbiol., 64 :575-580.

Keel, C., D. Weller and L. Thomashow. 1996. Conversion of the 2,4diacetylphloroglucinol biosynthesis locus among fluorescent Pseudomonas strains. Appl. Environ. Microbiol., 62: 552-563.

Palleroni, N. 1984. Genus 1. Pseudomonas (Migula 1894) P: 141-199. In N.R. Krieg and J.G. Holt (ed.) Bergey's manual of systematic bacteriology, Vol I. Williams and Wilkins, Baltimore, Md.

Palleroni, N. 1992. Human and animal pathogenic pseudomonas. P: 30863103. In A. Balows (ed.) The prokaryotes. Springer Verlag, New York, N. Y.

Palleroni, N. 1993. Pseudomonas classification. A new case history in the taxonomy of gram-negative bacteria. Anton. Leeuwen., 64: 231-251.

Park, S. C., I. Shimamura, M. Fukunaga, K. I. Mori and T. Nakai. 2000 Isolation of bacteriophages specific to a fish pathogen Pseudompnas plecoglossicida, as a candidate for disease control. Applied and Environmental Microbiol., 66: 1416-1422. 
Sharma, R. S., A. Mohmmed and C. R. Babu. 2002. Diversity among rhizobiophages from rhizospheres of legumes iinhabiting three ecogeographical regions of india. Soil B iology and Biochemistry, 34 :965-973.

Stead, D. (1992): Grouping of plant-pathogenic and some other Pseudomonas spp. by using cellular fatty acid profiles. Int. J. Syst. Bacteriol., 42: 281-295.

Taeok B., B. Tadashi, H. Keiichi and S. Olaf. 2006. Prophage of Staphylococcus aureus. Newman and their contribution to virulence. Molecular Microbiology, 62: 1035-1047.

Toth, I. H., Schmid, M. Dow, A. Malik, E. Oswald and B. Nagy. 2003. Transduction of enteropathogenic Escherichia coli with a derivative of a shiga toxin 2-encoding bacteriophage in a porcine ligated ileal loop system. Applied and environmental Microbiol. , 69 :7242-7247.

Widmer, F., R. Seidler, P. Gillevet and G. Di giovanni (1998): A high selective PCR Protocol for detecting 16S rRNA genes of the genus Pseudomonas in environmental samples. Appl. Environ. Microbiol., 64: 2545-2553.

دراسات وراثية ميكروبية لبكتريا Pseudomonas aeruginosa معزولة

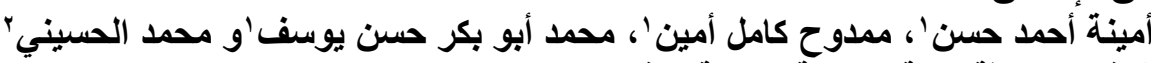

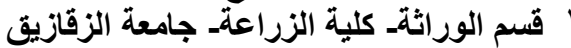

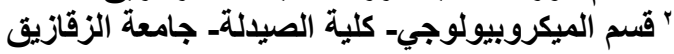

استخدمت بكتريـا Pseudomonas aeruginosa التـي عزلت مـن الإنسـان لدراسـة بعض

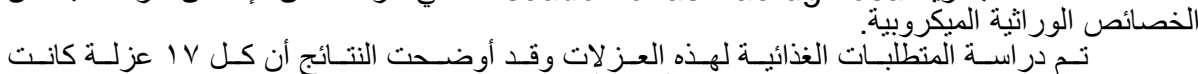

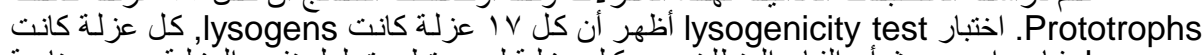
lysogen

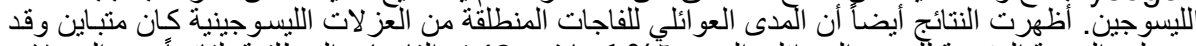

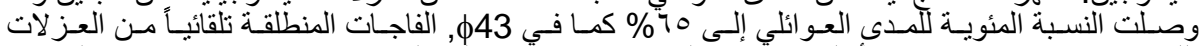

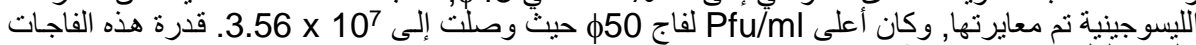
على تحليّل سلالات قياسية من بكتريا

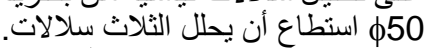

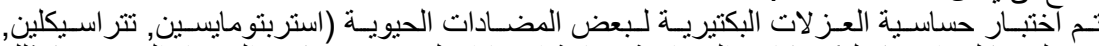

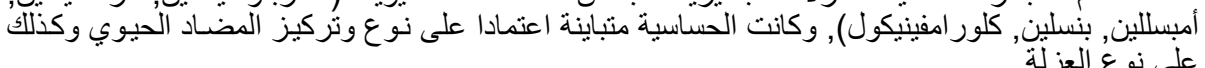

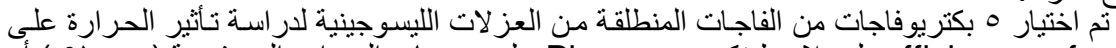

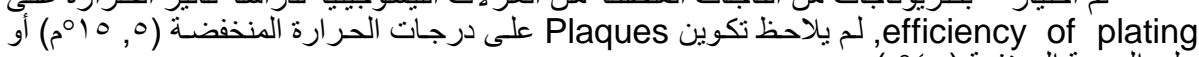

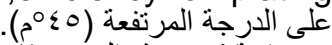

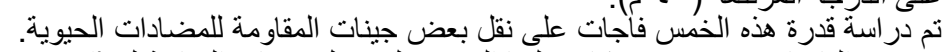

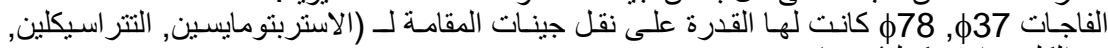

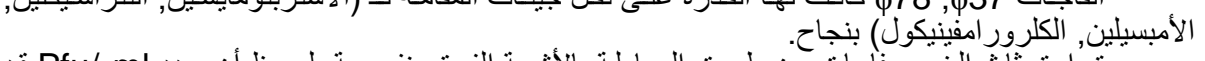

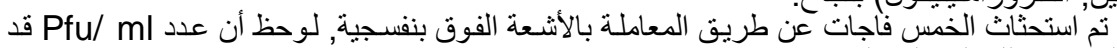

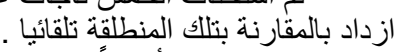

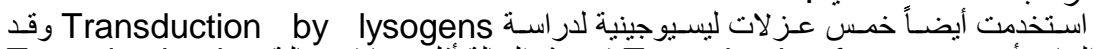

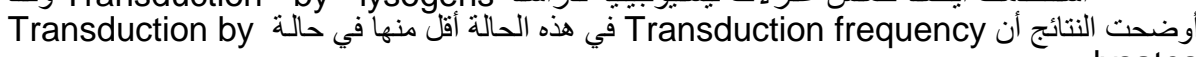

.lysates 

Table 3 : Lysogenesity test of $\boldsymbol{P}$. aeruginosa bacterial cells isolated from human.

\begin{tabular}{|c|c|c|c|c|c|c|c|c|c|c|c|c|c|c|c|c|c|}
\hline Host Phage & $\phi 1$ & $\phi 11$ & $\phi 17$ & $\phi 37$ & $\phi 43$ & $\phi 45$ & $\phi 50$ & $\phi 58$ & $\phi 68$ & $\phi 70$ & $\phi 76$ & $\phi 77$ & $\phi 78$ & $\phi 87$ & $\phi 111$ & $\phi 113$ & $\phi 114$ \\
\hline ATC 1 & - & - & - & - & - & - & - & - & - & - & - & - & - & - & - & - & - \\
\hline ATC 11 & - & - & - & - & + & - & - & - & - & - & - & - & - & - & - & - & + \\
\hline ATC 17 & - & - & - & - & - & - & - & + & - & - & - & + & - & - & + & - & - \\
\hline ATC 37 & + & - & - & - & + & - & - & - & - & - & - & - & - & + & - & - & - \\
\hline ATC 43 & + & + & + & - & - & + & + & + & + & + & + & - & + & + & + & + & + \\
\hline ATC 45 & - & - & - & - & + & - & + & + & + & - & - & - & - & - & + & - & + \\
\hline ATC 50 & - & - & + & - & - & - & - & + & - & + & - & - & - & - & - & - & - \\
\hline ATC 58 & - & + & + & + & + & + & + & - & - & + & - & + & + & - & + & - & + \\
\hline ATC 68 & + & - & - & - & - & - & + & - & - & + & - & + & - & - & - & + & - \\
\hline ATC 70 & - & - & + & - & + & + & - & - & - & - & - & + & + & - & + & - & + \\
\hline ATC 76 & - & + & - & + & + & + & - & + & - & + & - & + & + & - & - & - & + \\
\hline ATC 77 & - & - & - & + & + & + & + & + & - & + & - & - & + & - & - & - & + \\
\hline ATC 78 & - & - & - & + & + & + & + & - & - & + & + & + & - & - & + & + & + \\
\hline ATC 87 & - & - & + & + & + & + & - & - & + & + & + & - & + & - & + & + & + \\
\hline ATC 111 & - & - & - & - & + & - & - & - & - & - & - & - & - & - & - & - & - \\
\hline ATC 113 & + & + & + & + & - & + & + & + & + & + & - & + & + & + & + & - & + \\
\hline ATC 114 & - & - & - & + & + & + & - & - & - & - & - & + & - & - & + & + & - \\
\hline
\end{tabular}

Table 4: Host range of released phage spontaneously from lysogen.

\begin{tabular}{|c|c|c|c|c|c|c|c|c|c|c|c|c|c|c|c|c|c|}
\hline Host $\quad$ Phage & $\phi 1$ & $\phi 11$ & $\phi 17$ & $\phi 37$ & $\phi 43$ & $\phi 45$ & $\phi 50$ & $\phi 58$ & $\phi 68$ & $\phi 70$ & $\phi 76$ & $\phi 77$ & $\phi 78$ & $\phi 87$ & $\phi 111$ & $\phi 113$ & $\phi 114$ \\
\hline ATC & 37 & 43 & 43 & 58 & 11 & 43 & 43 & 17 & 43 & 43 & 43 & 17 & 43 & 37 & 17 & 43 & 11 \\
\hline ATC & 43 & 58 & 50 & 76 & 37 & 58 & 45 & 43 & 45 & 50 & 78 & 58 & 58 & 43 & 43 & 68 & 43 \\
\hline ATC & 68 & 76 & 58 & 77 & 45 & 70 & 58 & 45 & 87 & 58 & 87 & 68 & 70 & 113 & 45 & 78 & 45 \\
\hline ATC & 113 & 113 & 70 & 78 & 58 & 76 & 68 & 50 & 113 & 68 & & 70 & 76 & & 58 & 87 & 58 \\
\hline ATC & & & 87 & 87 & 70 & 77 & 77 & 76 & & 76 & & 76 & 77 & & 70 & 114 & 70 \\
\hline ATC & & & 113 & 113 & 76 & 78 & 78 & 77 & & 77 & & 78 & 87 & & 78 & & 76 \\
\hline ATC & & & & 114 & 77 & 87 & 113 & 113 & & 78 & & 113 & 113 & & 87 & & 77 \\
\hline ATC & & & & & 78 & 113 & & & & 87 & & 114 & & & 113 & & 78 \\
\hline ATC & & & & & 87 & 114 & & & & 113 & & & & & 114 & & 87 \\
\hline ATC & & & & & 111 & & & & & & & & & & & & 113 \\
\hline ATC & & & & & 114 & & & & & & & & & & & & \\
\hline No. lysed host & 4 & 4 & 6 & 7 & 11 & 9 & 7 & 7 & 4 & 9 & 3 & 8 & 7 & 3 & 9 & 5 & 10 \\
\hline$\%$ of host range & 24 & 24 & 35 & 41 & 65 & 53 & 41 & 41 & 24 & 53 & 18 & 47 & 41 & 18 & 53 & 29 & 59 \\
\hline
\end{tabular}


Hassan, Amina A.et al. 